\title{
A contribuição do cinema para a memória da ditadura brasileira*
}

\author{
Christa Berger \\ Professora do Programa de Pós-graduação em Ciências da Comunicação da Unisinos. \\ Pesquisadora CNPq. Doutora em Ciências da Comunicação pela ECA-USP. \\ E-mail: christab@unisinos.br \\ Juliana Campos Chaves \\ Bolsista de Iniciação Científica do Programa de Pós-graduação em Ciências da Comunicação \\ da Unisinos. Estudante de Comunicação Social - habilitação Jornalismo, na Unisinos. \\ E-mail: juchaves1985@gmail.com
}

Resumo: A ditadura militar que vai de 1964 a 1980 é um acontecimento marcante da vida política brasileira e está registrada em diferentes formatos e expressões culturais. Neste artigo, relacionamos a memória traumática brasileira ao circuito da memória mundializada. A amostra de 34 filmes produzidos no Brasil com menções à ditadura possibilita situar a questão da memória oficial e as memórias subterrâneas e problematizar as funções da memória nos formatos da Indústria Cultural.

Palavras-chave: memória, memória midiática, memória subterrânea, cinema, ditadura.
Abstract: The military dictatorship which goes from 1964 to 1980 is a landmark event of Brazilian politics and is registered in different forms and cultural expressions. In this text, we relate a traumatic memory to the Brazilian circuit of global memory. The sample of 34 films produced in Brazil in terms of dictatorship allows it to question the official memory and the underground memories and discuss the function of memory in the Culture Industry context.

Keywords: memory, midiatic memory, underground memory, cinema, dictatorship.

"A política mais importante é a que fazemos com os olhos."

Recebido: 07.10.2008

Aprovado: 31.03 .2009

A história brasileira, em conjunto com a argentina, chilena e uruguaia, contribuiu com a cota de sofrimento provocado por decisões políticas que perpassaram o século XX. Os que testemunharam essas experiências têm conquistado um espaço de escuta e introduzido, também, entre nós, o problema de pensar sobre a função da memória.

O tempo regido pelos militares vem reaparecendo aos poucos fora da história oficial: são livros biográficos, programas de TV, notícias dos eventos que registram a passagem do tempo. Filmes não param de estrear e repercutem como cinema de memória. Na sala de aula os livros de história recebem
* Este trabalho conta com o apoio do Conselho Nacional de Desenvolvimento Científico e Tecnológico - CNPq - Brasil.

1. WENDERS, Wim, apud LABAKI, Amir. É tudo verdade: reflexões sobre a cultura do documentário. São Paulo: Francis, 2005. 
2. GAGNEBIN, Jean Marie. Lembrar, escrever, esquecer. São Paulo: Editora 34, 2006.

3. HALBWACHS, Maurice. A memória coletiva. 2 . ed. São Paulo: Centauro Editora, 2004.

4. POLLAK, Michael. Memória, esquecimento, silêncio. Estudos Históricos, Rio de Janeiro, v. 2, n. 3, 1989 o reforço das imagens que contribuem para uma representação sensível dos anos de chumbo.

Quando começa o processo de democratização inicia-se, também, a necessidade de esclarecer o que aconteceu durante o regime militar nesses países. São quase simultâneas as manifestações políticas pela abertura e as expressões culturais de representação da ditadura. A história vai sendo passada a limpo, por distintas motivações, através de diferentes suportes e disponibilizada para uma parcela da população não diretamente afetada pelos fatos. Ao lembrar da ditadura e das lutas contra ela, a pretensão é que a tirania não se repita, que a ausência de democracia seja lamentada e que os sujeitos que lutaram contra ela sejam lembrados.

Uma política de memória propõe não deixar esquecer (os sobreviventes têm obrigação de contar), lembrar para não voltar a acontecer (o passado retorna ao presente na perspectiva do futuro), e tem como paradigma-fundador Auschwitz. A América Latina que conheceu a experiência de ditadura militar absorveu esta referência, deixou passar o tempo em que as feridas não autorizam a narrativa e, então, iniciou seu processo de rememoração. O Brasil, a Argentina, o Chile e o Uruguai estão produzindo suas memórias traumáticas nacionais. Por um lado, porque o tempo de vida dos sobreviventes motiva a pressa na narrativa testemunhal. Por outro, porque a cultura midiática atenta aos movimentos da sociedade, vislumbra o interesse pela memória e investe na produção memorialística como produto de consumo.

Assim, vem sendo produzida a cultura da memória da ditadura no Brasil: ela se inscreve no movimento internacional que recorda traumas nacionais; ela conta, para a sua produção, com os relatos das testemunhas da época; ela acontece na mídia ou através dos suportes midiáticos disponíveis e carrega as ambiguidades da triangulação entre lembrar, esquecer e narrar. E deixa suspensa a pergunta sobre as possibilidades de a cultura produzida nos suportes midiáticos iluminar e esclarecer o acontecido.

\section{QUESTÕES PARA ABORDAR A MEMÓRIA}

A questão da memória perpassa diversas disciplinas. Como aponta Gagnebin ${ }^{2}$, apesar de tão antiga como a poesia homérica, a memória assume hoje traços muito específicos. Como não estamos mais inseridos em uma tradição de comunidade oral, comunitária e de comunicação direta, precisamos inventar estratégias de conservação e mecanismos de lembrança, diz Maurice Halbwachs ${ }^{3}$. Criamos, então, museus e centros de memória; recolhemos fotografias, documentos, resquícios do que aconteceu; editamos livros e publicações especiais comemorativos; produzimos imagens em vídeo e filme - tudo para garantir o não esquecimento.

Se, por um lado, existe a tendência à documentação pelo desejo de guardar as vivências, há acontecimentos históricos que exigem o não esquecimento, a obsessão necessária, poderíamos dizer. Pollak ${ }^{4}$ lembra que o estudo que privi- 
legia os excluídos, as minorias, os marginalizados vai produzir uma memória que se contrapõe à memória oficial. Para ele, há memórias subterrâneas que disputam sentidos com outras e, por isso, a memória coletiva não é consensual. Em qualquer contexto é impossível encontrar uma visão e uma interpretação única do passado, compartilhada por toda a sociedade. Temos muitos exemplos históricos de memórias traumáticas, proibidas, clandestinas que ficaram guardadas esperando o momento propício para se expressar. O problema para as memórias subterrâneas, clandestinas e inaudíveis é passar do não dito à exposição. Quando chegou o momento dos protagonistas-testemunhas da ditadura no Brasil iniciarem seu processo de lembrança pública, eles confrontaram suas lembranças com a memória dos militares, provocando uma disputa de sentidos que vai além do discurso. Ao dizerem das torturas, repressão e censura, queriam afirmar uma outra possibilidade de fazer política no País e, queriam, também, justiça. A exigência dos corpos das vítimas, os pedidos de reparação, a identificação dos torturadores para levá-los a julgamento acompanharam a narrativa das testemunhas. Para eles, o sentido do retorno ao passado está na lei e na justiça.

A memória dos passados traumáticos tem momentos de maior visibilidade e momentos de silenciamento. O aparecimento de novos atores ou o surgimento de alguma nova informação podem provocar o reaparecimento do passado com novas significações. É o que podemos considerar como as camadas que cobrem o acontecido e que vão sendo descobertas ou destapadas ao longo do tempo por diferentes motivações. Mas ela também retorna motivada pela lógica da produção cultural midiática, que investe na exposição e visibilidade dos sentimentos.

A história dos totalitarismos do século XX - nazismo, fascismo, stalinismo, ditaduras militares - está contada de todos os lados, dos vencidos e dos vencedores, dos que mandaram e dos que obedeceram. Tudo hoje nos é dado a conhecer formando um quadro de muitas caras, vozes e tonalidades que vêm ao encontro da observação de Benjamin, "nada do que aconteceu pode ser perdido para a história". Ao que podemos acrescentar: nada do que tem potencial para o espetáculo pode ser desprezado pela mídia. A cultura da memória reúne as duas orientações - da história e da mídia -, complexificando a questão da necessidade de lembrar.

A pesquisa sobre o lugar que a memória ocupa na cultura política contemporânea passa por todas estas questões e acrescenta mais uma para os pesquisadores da comunicação que, observando a cultura midiática da memória, perguntam pela possibilidade de ela cumprir a recomendação de Todorov $^{6}$ - o trabalho de memória se submete a duas exigências: fidelidade ao passado e utilidade ao presente. A memória midiática tem sido fiel ao passado, e qual pode ser a utilidade da memória quando enunciada como espetáculo?

\section{A DITADURA NA TELA DE CINEMA}

O período que vai de 1964 a 1980 ficou por um bom tempo na memória subterrânea e clandestina no Brasil. Porque como toda memória traumática é,
5. BENJAMIN, Walter. Sobre o conceito de História. In: Magia e técnica, arte e política: ensaios sobre literatura e história da cultura. 6. ed. São Paulo: Brasiliense, 1993. v. 1: Obras Escolhidas.

6. TODOROV, T. Memoria del mal, tentación del bien (Memória do mal, tentação do bem). Indagación sobre el siglo XX. Barcelona, Península, 2005. 
7. POLLAK, op. cit., p. 12.

8. Ver: KURTZ, Adriana. O destino da memória das vítimas da Shoah na cinematografia de um mundo administrado. 2007. Tese (Doutorado em Comunicação e Informação)-Faculdade de Biblioteconomia e Comunicação, Universidade Federal do Rio Grande do Sul, Porto Alegre, 2007.

9. O bom burguês (1979); Greve! (1979); O caso Claudia (1979); ABC da greve (1979); Não se cala a consciência de um povo (1979); Eles não usam black tie (1981) Linha de montagem (1982): Pra frente Brasil (1983); Cabra marcado para morrer (1984); Jango (1984); Nunca fomos tão felizes (1984); Céu aberto (1985); O homem da capa preta (1986): Que bom te ver viva (1989); Anos rebeldes (1992); Lamarca (1994); As meninas (1995); O que é isso, companheiro? (1997): Ação entre amigos (1998); Dois córregos (1999); Barra 68, sem perder a ternura (2000): Araguaya - a conspiração do silêncio (2004): Yã Katu - O Brasil dos Villas Boas (2004); Quase dois irmãos (2005): Vlado: 30 anos depois (2005); Cabra-cega (2005); Hércules 56 (2006); $O$ ano em que meus pais saíram de férias (2006): Sonhos e desejos (2006); O Sol - Caminhando contra o vento (2006); Zuzu Ange (2006); 1972, de José Emílio Rondeau (2006): Batismo de sangue (2007); Caporaó (2007).

10. XAVIER, Ismael. Do golpe militar à abertura: a resposta do cinema de autor. In: $O$ desafio do cinema. Rio de Janeiro: Zahar, 1985. num primeiro momento, indizível. Depois foi cochichada entre os iguais para ir aparecendo devagarzinho fora da história oficial - esta que queria tão somente esquecer. Na primeira oportunidade chegou através dos livros de testemunho e do cinema. A comemoração dos aniversários do acontecido em 1964 mereceu, regularmente, notícia no jornalismo. No dia 31 de março de 1974 os jornais noticiaram os 10 anos da revolução, o mesmo aconteceu no dia 31 de março de 1984. Mas nos 40 anos, a revolução dos militares ganhou em todos os jornais o nome de golpe, designação que corresponde à memória subterrânea.

A produção jornalística é exemplar da relação entre os enquadramentos, as fontes e os contextos específicos. Em 1974, a ditadura estava vigorosa, então os jornais expressavam a opinião dos militares: eles protagonizaram uma revolução. Em 1994, em pleno processo de democratização da sociedade brasileira, os jornais enunciam a partir da perspectiva política hegemônica, e a revolução passa a ser um golpe.

Pollak considera o cinema o meio mais apropriado para expandir a memória.

Nas lembranças mais próximas, aquelas de que guardamos recordações pessoais, os pontos de referência geralmente são de ordem sensorial: o barulho, os cheiros, as cores... Ainda que seja tecnicamente difícil ou impossível captar todas essas lembranças em objetos de memória confeccionados hoje, o filme é o melhor suporte para fazê-lo: donde seu papel crescente na formação e reorganização, e, portanto, no enquadramento da memória. Ele se dirige não apenas às capacidades cognitivas, mas capta as emoções [...]. O filme-testemunho e documentário tornou-se um instrumento poderoso para os rearranjos sucessivos da memória coletiva e, através da televisão, da memória nacional7 .

Se a constatação de Pollak é confirmada pelos filmes da Shoah, ela também se adéqua ao caso da ditadura brasileira ${ }^{8}$. O cinema e a televisão enquadraram a memória, oficial e subterrânea, e foram constituindo um consenso tenso sobre aquele tempo. Em nossa pesquisa sobre as manifestações culturais da ditadura, localizamos 34 filmes produzidos entre 1979 e 2008, e eles estão classificados em 23 de ficção e 11 documentários .

Os primeiros filmes apenas insinuam a existência da ditadura. Em $O$ bom burguês, de Oswaldo Caldeira, José Wilker é um bancário que desvia dinheiro do banco em que trabalha para financiar a organização de esquerda a que pertence. No mesmo ano, O caso Claudia, de Miguel Borges, mostra os obstáculos à investigação sobre a morte de uma jovem por estarem envolvidos filhos dos que mandam no País.

Documentários como Greve, de João Batista de Andrade, Não se cala a consciência de um povo, de Jorge Cláudio Ribeiro, e $A B C$ da greve, de Leon Hirszman, também foram lançados logo no início da abertura. Nesses, a ênfase está no relato da resistência e da organização que começa a construir o processo de democratização.

Na década de 1980, a tendência continua e Ismail Xavier a descreve pelo nome de "naturalismo da abertura" ${ }^{10}$. Um cinema policial-político de cunho naturalista que se valeria de fórmulas tradicionais para tratar dos anos de chumbo. 
A abertura política está sendo comemorada e o tempo da ditadura é mostrado no seu início em $O$ homem da capa preta, de Sérgio Rezende, que conta o fim do populismo interrompido pelo golpe; Prá frente Brasil, de Reginaldo Farias, mostra cenas de tortura enquanto o Brasil vibra com a seleção brasileira na copa de 1970, e o documentário Que bom te ver viva traz relatos de ex-presas políticas, que contam o que passaram na prisão. Também pertencem ao naturalismo da abertura os filmes: Eles não usam black tie, de Leon Hirszman, e Nunca fomos tão felizes, de Murilo Sales. Eles dividem a década com os documentários Linha de montagem, de Renato Tapajós, Cabra marcado para morrer, de Eduardo Coutinho, Jango, de Silvio Tendler, e Céu aberto, de João Batista de Andrade.

Contudo, o filme que melhor permite a reflexão sobre a constituição das camadas da memória é Cabra marcado para morrer, de Eduardo Coutinho. Ele conta a história política do líder da liga camponesa de Sapé (Paraíba), João Pedro Teixeira, assassinado em 1962. Por causa do golpe, as filmagens foram interrompidas. Dezessete anos depois, o diretor retorna à região e reencontra a viúva de João Pedro, Elisabeth Teixeira. Essa obra sobreviveu à censura e ao silêncio, sendo um marco para o cinema brasileiro. Nele se confunde a história do líder morto em 1962 e a interrupção do filme sobre ele em 1964. História e cinema voltam no tempo interrompido pelos mesmos censores, refazendo através da lembrança dos protagonistas o que ficou suspenso pelo arbítrio.

No movimento que se denominou "retomada do cinema brasileiro"11, na década de 1990, marcado pelos reflexos da Lei do Audiovisual e por novas possibilidades para a produção cinematográfica brasileira, outra vez a ditadura teve forte presença. Lamarca, de Sérgio Rezende, e $O$ que é isso, companheiro?, de Bruno Barreto, tratam em primeiro plano da guerrilha e foram sucesso de público. Provocaram debates acirrados pela verossimilhança com o acontecido e pela narrativa próxima dos filmes de ação norte-americanos. Outros fizeram menos sucesso, mas também abordaram a questão da clandestinidade, como Ação entre amigos, de Beto Brant, e Dois córregos, de Carlos Reichenbach.

A produção continuou intensa nos anos 2000. Quase dois irmãos, de Lucia Murat, e Cabra-cega, de Toni Venturi, estrearam em 2005. Também esses filmes falam da adesão à guerrilha, mas sem a glorificação da ação dos protagonistas nem mistificações sobre o período, como Lamarca e $O$ que é isso, companheiro? Nestes, a escolha pela luta armada é questionada e erros e equívocos não são minimizados.

Em 2006, O Sol - caminhando contra o vento, de Tetê Moraes, conta a experiência da produção do jornal alternativo $O$ Sol, que circulou de setembro de 1967 até janeiro de 1968. É um filme-documentário em que intelectuais e artistas se reencontram para falar da experiência da produção do jornal, cerca de 40 anos depois. Zuzu Angel, de Sérgio Rezende, lançado no mesmo ano, reconstrói a história ocorrida três anos depois do fechamento do jornal e quando ninguém mais duvida do que os militares são capazes de fazer. A narrativa se passa em 1971, quando Stuart Angel Jones é morto em um quartel em que muitos jovens, como ele, estão presos e são torturados. O filme conta a história da mãe que
11. NAGIB, Lúcia. O cinema da retomada: depoimentos de 90 cineastas dos anos 90. Rio de Janeiro: Editora 34, 2002. 
comunicação \& educação • Ano XIV • Número 3 • set/dez 2009

luta contra a versão oficial e o que acontece a ela por buscar esclarecer a morte do filho. A memória do que ocorreu a Stuart e a Zuzu disputa com a versão oficial da morte do filho e do acidente de carro da mãe.

Dois filmes em 2006 descrevem a conjuntura política da ditadura através do olhar de quem não é protagonista dos fatos. $O$ ano em que meus pais saíram de férias, de Cao Hamburger ${ }^{12}$, traz a história de um menino, filho de militantes, que é obrigado a ficar longe dos pais, e 1972, de José Emílio Rondeau, aproxima os anos da ditadura ao amor adolescente. Em 2007, outros dois filmes entraram no circuito cinematográfico. Caparaó, de Flávio Frederico, e Batismo de sangue, de Helvécio Ratton, baseado no livro do Frei Beto.

Todos estes filmes elegem a perspectiva dos que sofreram a ação da ditadura, são sensíveis (em diferentes graus) às histórias narradas e contribuem para fazer emergir a memória subterrânea.

Já o filme Casseta e Planeta - a taça do mundo é nossa, de Lula Buarque de Hollanda, propõe uma abordagem que se aproxima da memória oficial. Com a justificativa de ser humorístico, banaliza o sofrimento da época, ridiculariza os que optaram pela luta armada e termina com a simulação de um debate com o público em que ninguém é capaz de propor uma questão pertinente aos artistas.

Os personagens que representam a esquerda são um comunista ignorante (ele escreve abaicho a ditadura em uma pichação), um hippie vegetariano que só pensa em fumar maconha, um artista que quer ser famoso - o personagem imita Roberto Carlos - e a filha de um militar que se apaixona por um militante e, por isso, decide lutar contra o governo.

Os integrantes do movimento se conhecem em uma churrascaria. Eles roubam a taça de Campeão do Mundo da seleção brasileira e se escondem no sítio da filha do militar. Lá eles decidem o nome do partido. Após várias tentativas absurdas para a escolha, eles chegam a PANAC. Nesse momento alguém diz: "Muito próprio para esse movimento". E todos aplaudem e concordam com a sigla. É com a imagem de uma população incapaz e imbecil que o filme argumenta e justifica o uso da força e, em última instância, o regime militar.

12. Entrevista concedida a este periódico. Ver: COSTA, Cristina; IVO, Consuelo. Um filme com muitas portas. Revista Comunicação \& Educação. São Paulo: CCA-ECA-USP/ Paulinas, ano XII, n. 2 maio/ago. 2007. [N.E.]

\section{O JORNALISMO NOS FILMES DA DITADURA}

Em 1996, Lúcia Murat dirigiu um filme sobre os bastidores de uma emissora de televisão e sua cobertura em uma campanha política. Sem se apresentar como um documentário, fazia referência a fatos conhecidos na campanha para presidência no ano anterior. Doces poderes mostra as sequelas da ditadura no setor das comunicações e dialoga com $\mathrm{O}$ Sol - alterando o tempo cronológico. Primeiro, assistimos ao que está próximo, ao que acaba de acontecer e que nos situa diante do sistema de comunicação no Brasil, fruto das decisões do período da ditadura militar: a concentração econômica dos meios, a hegemonia da televisão, o agendamento da política pelos profissionais de campanhas de marketing. Modalidades inauguradas pelo modo midiático de fazer política. Esse jeito suplantou 
(ou enterrou) as propostas da imprensa alternativa e da comunicação popular que vigoraram antes e durante a ditadura e que são retratadas em $O$ Sol. A ideia de uma imprensa nanica, realizada coletivamente, sem pretensão de ser a única fonte de informação ou enriquecer seus idealizadores não frutificou. Quando o filme termina é inevitável pensar em como seria o Brasil se o projeto de $O$ Sol (e de tantas outras publicações assim pensadas) tivesse vingado. Quando o filme apresenta o jornal através do testemunho dos que o idealizaram e produziram, estamos em contato com a memória subterrânea colocada em circulação nacional, que disputa a memória da história da grande imprensa e que fala do Brasil de antes dos anos de chumbo, quando intelectuais e artistas se reuniam para dar respostas inclusivas e idealistas para os problemas do País.

Entre $O$ Sol (década de 1960) e Doces poderes (década de 1990) muita coisa aconteceu. Inclusive a morte do jornalista Vladimir Herzog, que também está registrada em um documentário: Vlado: 30 anos depois.

Ao narrar o tempo da ditadura, as personagens se alternam entre militantes e militares; os que sofrem e os que praticam a tortura; os que propõem ações para organizar o povo e os que interrompem esta intenção. A imprensa, que tem a função de descrever o tempo presente, censurada pela ditadura, não assume o papel de mediador entre as partes e, por isso, ela existe através do não dito. Não há menção à imprensa no filme Zuzu Angel. A falta é sintomática. Há uma denúncia, há uma mãe que circula por todos os lugares atrás de seu filho, há a suspeita de uma morte horrível. Mas não há vestígios dessa informação na imprensa. Aqui caberia o jornalista heroico da atuação no Caso Claudia, ou o jornalista intelectual do cinema novo. Mas não há investigação jornalística quando a censura pauta a produção e a morte aguarda os que resistem. O que é confirmado pela morte de Vlado que acontece, de fato, entre a criação de $O$ Sol e de Doces poderes.

Iniciamos observando que a memória da ditadura brasileira participa do movimento internacional que fez emergir as memórias traumáticas. Participamos, também, com os 34 filmes, para constatação de que o cinema é um meio importante para registrar o passado. A imagem dos campos de concentração, assim como as cenas de tortura, acompanhadas do olhar angustiado, dos gritos do policial, do corpo amedrontado, vão formando um arquivo de imagens da dor, que se repetem, em princípio, pela orientação de que nada do que aconteceu deve ser perdido para a história e que narrar cura e esclarece. Mas, também, a memória pode pretender, pela repetição, apagar o espanto e a perplexidade. Zygmunt Bauman ${ }^{13}$ observa que os filmes produzidos pela indústria do Holocausto tiraram o tema das salas de arte e os trouxeram para os shoppings centers e, agora, os espectadores podem assistir a histórias deste tema sem prejudicar seu lanche de pipoca e refrigerante.

Esta é a questão que fica suspensa para a pergunta da função da memória midiatizada. Inevitável a suspeita de que ela possa cumprir o papel de, ao lembrar, contribuir para naturalizar e, assim, descumprir a razão de ser da memória subterrânea.

O paradoxo destes tempos de reavivamento e circulação ininterrupta de memórias é: lembrar para esclarecer ou lembrar para esquecer?
13. BAUMAN, Zygmunt. Modernidade e Holocausto. Rio de Janeiro: Zahar, 1998. 
comunicação \& educação • Ano XIV • Número 3 • set/dez 2009

\section{REFERÊNCIAS BIBLIOGRÁFICAS}

BAUMAN, Zygmunt. Modernidade e Holocausto. Rio de Janeiro: Zahar, 1998.

BENJAMIN, Walter. Sobre o conceito de História. In: Magia e técnica, arte e política: ensaios sobre literatura e história da cultura. 6. ed. São Paulo: Brasiliense, 1993. v. 1: Obras Escolhidas.

COSTA, Cristina; IVO, Consuelo. Um filme com muitas portas. Revista Comunicação \& Educação. São Paulo: CCA-ECA-USP/Paulinas, ano XII, n. 2, maio/ago. 2007.

GAGNEBIN, Jean Marie. Lembrar, escrever, esquecer. São Paulo: Editora 34, 2006.

HALBWACHS, Maurice. A memória coletiva. 2. ed. São Paulo: Centauro Editora, 2004.

KURTZ, Adriana. O destino da memória das vítimas da Shoah na cinematografia de um mundo administrado. 2007. Tese (Doutorado em Comunicação e Informação)-Faculdade de Biblioteconomia e Comunicação, Universidade Federal do Rio Grande do Sul, Porto Alegre, 2007.

LABAKI, Amir. É tudo verdade: reflexões sobre a cultura do documentário. São Paulo: Francis, 2005.

NAGIB, Lúcia. O cinema da retomada: depoimentos de 90 cineastas dos anos 90 . Rio de Janeiro: Editora 34, 2002.

POLLAK, Michael. Memória, esquecimento, silêncio. Estudos Históricos, Rio de Janeiro, v. 2, n. 3, 1989.

TODOROV, T. Memoria del mal, tentación del bien (Memória do mal, tentação do bem). Indagación sobre el siglo XX. Barcelona: Península, 2005.

XAVIER, Ismael. Do golpe militar à abertura: a resposta do cinema de autor. In: O desafio do cinema. Rio de Janeiro: Zahar, 1985. 